\title{
Producción social del espacio y procesos rituales: Análisis de la práctica de la diana en San Pedro de Barva
}

\author{
Marco González
}

\author{
Escuela de Ingeniería Industrial, Facultad de Ingeniería, Universidad de Costa Rica \\ marcos.gonzalezviquez@ucr.ac.cr
}

\begin{abstract}
Resumen: El siguiente artículo se deriva de la investigación denominada "Espacio, ritual y estructura social: el amanecer de los mantudos y la espantaperros", realizada en el programa de maestría en Antropología de la Universidad de Costa Rica. Los resultados han sido producto del trabajo etnográfico entre el 2011 y 2013. Se propone que la producción social del espacio no solamente se relaciona con la interacción de formas económicas locales y globales, sino que responde además a las continuidades y rupturas entre prácticas simbólicas que engendran y mantienen la noción de identidad local. Se podría decir entonces que esta es una de las características del cambio sociocultural que deriva en transformación del territorio y las estructuras sociales que lo definen.

Palabras clave: antropología, etnografía, máscaras, ritual, cultura.

Social production of space and ritual processes: Analysis of the practice of diana in San Pedro de Barva Abstract: The following article is derived from the research entitled, "Space, ritual and social structure: el amanecer de los mantudos y la espantaperros", fulfilled in the Master's in Anthropology program of the University of Costa Rica. The results were acquired through ethnographic work conducted between 2011 and 2013. It is proposed that the production of social space is not only indicative of the interaction of local and global economic forms, but also of the continuities and ruptures between symbolic practices that engender and preserve the notion of local identity. As such, it is one of the characteristics of sociocultural change that results in transformation of the territory and the social structures.
\end{abstract}

Keywords: anthropology, ethnography, ritual, culture, mask.

Cuadernos de Antropología

Enero-Junio 2015, 25(1), 47-66

DOI: $10.15517 /$ cat.v25i1.19768

Recibido: 12-07-2014 / Aceptado: 24-03-2015

Revista del Laboratorio de Etnología María Eugenia Bozzoli Vargas Escuela de Antropología, Universidad de Costa Rica http://revistas.ucr.ac.cr/index.php/antropologia ISSN 2215-356X

cc) (i) (-) Cuadernos de Antropología está bajo una licencia Creative Commons EY NC SA Attribution-NonCommercial-ShareAlike 3.0

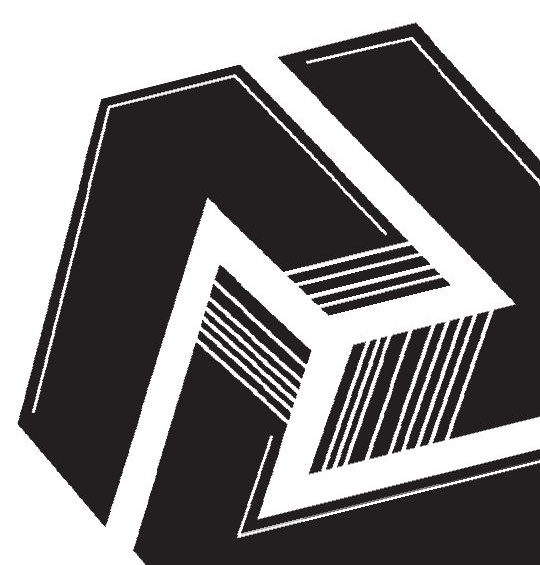




\section{Introducción}

El texto siguiente se enfoca en la relación entre espacio, identidad y procesos rituales. Mediante una propuesta de estructura teórica interpretativa, se presentan y discuten los principales resultados del trabajo etnográfico aplicado a la práctica tradicional de la diana en San Pedro de Barva, comunidad ubicada al norte del Valle Central, en la provincia de Heredia.

En Costa Rica, el calendario de las festividades religiosas sirvió de estrategia de las clases dominantes para consolidar en las nacientes comunidades las tradiciones, creencias y costumbres españolas. Las denominadas fiestas patronales en Costa Rica consisten en la celebración del día de un santo particular cuyo nombre define a la comunidad entre todas las demás. Usualmente, estas fiestas patronales tienen una mezcla de actividades religiosas y cívicas en las cuales se pueden ver representadas las diferentes clases sociales a partir de sus aportes y funciones en la planificación y desarrollo de la festividad misma. A pesar de que cada comunidad tiene su propia forma de celebrar estas fiestas, es común encontrar tradiciones como la misa, la procesión, el turno y la diana. Esta última consiste generalmente en un desfile tipo carnaval donde participan músicos, máscaras y gente recorriendo ciertas rutas también dotadas de significado (casas de familias particulares, principales caminos de la comunidad, etc.). La práctica de la diana sucede al amanecer del día cuando se celebra la festividad del santo patrono de la comunidad. En Barva, las dianas son una tradición fuertemente asociada a tres elementos importantes: la artesanía de máscaras, la música (cimarrona) y el llamado licor de contrabando. San Pedro de Barva no escapa a esto, no obstante, presenta sus propias significaciones y formas.

En el análisis de los procesos donde grupos sociales se construyen una idea de espacio o "lugar" con características identitarias, históricas y relacionales (Augé, 2000), es pertinente poner la mirada en aquellas actividades que por un momento específico redefinen las relaciones sociales y los espacios que las posibilitan, provocando un escenario diferente al cotidiano. Las tradiciones festivas en honor a los "santos patronos" de comunidades rurales de Costa Rica presentan múltiples formas de esto. Una de ellas es la denominada diana en honor al santo de la comunidad de San Pedro de Barva, en la provincia de Heredia, la cual sucede entre el 28 y 29 de junio.

San Pedro de Barva tiene características interesantes. Se encuentra actualmente en un proceso de transformación de su espacio social, económico y ambiental (una especie de transición de lo rural a lo urbano) debido a razones como: a) crecimiento de la población, b) cambio de uso del suelo, c) desarrollo de infraestructura pública y privada; en general, los efectos de la expansión de la llamada Gran Área Metropolitana1. En general, a partir de los censos del Instituto Nacional de Estadística y Censo (INEC, 2014), se muestra que el distrito de estudio experimentó tres fenómenos relacionados con población y vivienda: a) crecimiento poblacional

1 La Gran Área Metropolitana del Valle Central de Costa Rica es una metrópolis que incluye a las ciudades de San José, Alajuela, Cartago y Heredia, cuenta con aproximadamente 2,6 millones de habitantes y una superficie de $2044 \mathrm{~km}^{2}$ (INVU, 2012).

Cuadernos de Antropología 2015, 25(1), 47-66 / ISNN 2215-356X

http://revistas.ucr.ac.cr/index.php/antropologia 
absoluto (16\%), b) mayor crecimiento de la infraestructura habitacional (46\%) y c) disminución de la densidad poblacional por vivienda (-18\%). A partir de estas estadísticas, se posiciona a San Pedro de Barva como un distrito que en diez años (del 2000 al 2011) pasó casi totalmente de una categoría "rural" (100 \% en 2000) a "urbana" (97 \% en 2011) según el Instituto Nacional de Estadística y Censos de Costa Rica ( $\mathbb{N E C}, 2014$ ). De esta categorización institucional surgen inquietudes particularmente pertinentes para las ciencias sociales. ¿Qué es lo rural y lo urbano para la gente de San Pedro de Barva? ¿Cómo impacta esto en lo identitario? ¿Qué procesos sociales y económicos influyen en la transformación de los espacios? Y, finalmente, ¿cuáles son estructuras de relaciones sociales asociadas a estos procesos?

\section{Marco teórico de interpretación: "espacio y proceso ritual"}

Si se acepta la idea de que la producción social del espacio tiene no solamente como factores constitutivos la influencia de los modos de producción económica, sino que también guarda estrecha concordancia con la reproducción de identidades que posibiliten la cohesión social y sentido de pertenencia de grupos humanos a los espacios colectivamente producidos, se puede construir entonces una estructura teórica que se denominará "producción social de espacio, identidad y procesos rituales".

Este ordenamiento teórico se compone de un eje con dos conceptos fundamentales en sus extremos. En un lado se ubica el término "espacio", visto desde la teoría lefebvriana, es decir, las prácticas espaciales, las representaciones sobre los espacios y los espacios de representación (Lefebvre, 1991) en el sentido de que son resultado de "procesos". En el otro extremo se ubica la noción de "identidad cultural". Si se añade la pregunta, ¿a través de qué "procesos" se puede visualizar tanto producción de espacio como reproducción de identidad? se tiene entonces la necesidad de una categoría conceptual adicional que sirva de enlace entre los extremos del eje analítico.

Desde la antropología, se sabe que los grupos humanos en todos los periodos de la historia han desarrollado prácticas fuertemente significantes en las cuales se fortalecen e incluso resuelven componentes elementales del sistema cultural, ya sean pasos trascendentes en el estatus social, momentos especiales del calendario productivo, económico, político y religioso o la reafirmación de las instituciones mismas del sistema. En general, se trata de acciones colectivas y sistemáticas cuyo objetivo es mantener la validez de las representaciones culturales sobre la realidad, especialmente aquellas que tienen que ver con las nociones de "nosotros", "los otros", "donde" y "cuando". Puede decirse que los aportes de la teoría del "proceso ritual" (Turner, 1988) se vuelven sumamente pertinentes, por lo que el eje es atravesado por este último elemento.

Si se toma en cuenta que la identidad como patrón de referencia social requiere la confianza de los sujetos en la continuidad del grupo y por lo tanto también del espacio que generan y habitan y que el espacio estará influenciado por los modos de producción económica dominantes derivados de la interacción

entre sistemas locales como globales, se hace la siguiente pregunta: ¿cómo se manifiestan las nociones de 
identidad y espacio, cuando a partir de las dinámicas del modo de producción dominante (capitalismo), suceden transformaciones en las estructuras económicas locales, por ejemplo en un contexto de transición rural-urbano?

Sobre el asunto de cómo abordar los procesos donde se produce tanto "identidad" como "espacio social", se consideran pertinentes los aportes teóricos de Víctor Turner (1988) y Roberto Da Matta (2002) sobre proceso ritual. Sus trabajos han demostrado que los grupos culturales requieren que se "refresquen" y "actualicen" las posiciones en el campo de referencia social, para lo cual el ritual desempeña un papel básico. Es a través de los rituales como se lleva a cabo la reafirmación del sistema y por tanto se pueden entender los discursos simbólicos sobre la estructura social (Da Mata, 2002). En la misma línea, Van Gennep (citado por Turner, 1988) propone una serie de términos asociada a los procesos rituales donde las categorías espacio y tiempo toman formas diferentes a las cotidianas sin que signifique una transformación irreversible del estatus de los sujetos (rito de paso). Precisamente las tres fases para esta clase de ritos Van Gennep les denomina a) preliminal: entendida como el momento de separación de las personas de las acciones y el estatus social cotidianos; b) liminal: espacio temporal separado de los procedimientos normales de la acción social, puede contemplarse potencialmente como un periodo de revisión exhaustiva de los axiomas y valores centrales de la cultura en que se produce (Turner, 1988) y c) posliminal: fase en la cual el colectivo social se reagrupa en torno a la estructura cotidiana reafirmada o incluso resuelta de conflictos anteriores. El valor epistémico de esta categorización propuesta por Van Gennep consiste precisamente en que permite una aproximación analítica de la diana a manera de "proceso", es decir, acción que puede visualizarse en términos de inicio-desarrollo-desenlace del ritual.

El asunto de la liminalidad, explica Turner, debe entenderse como lugares y tiempos alejados de la normalidad cotidiana. Físicamente pueden ser los mismos espacios, sin embargo, durante la liminalidad sobre ellos sucede una especie de revisión y reafirmación de los "axiomas y valores centrales de la cultura en que se produce" (Turner, 1988, p. 171). En este sentido, la diana se muestra como un "proceso ritual" que "produce" espacio.

Los insumos para esta descripción se basan en una estrategia metodológica que destaca el uso de las entrevistas a profundidad realizadas a las y los informantes clave, además de las prácticas de observación simple y participante en las dianas entre el 2011 y 2013. Otras fuentes no menos importantes permitieron análisis fotográfico y audiovisual a partir de registros anteriores al 2010. Luego, desde la perspectiva cuantitativa, el uso de herramientas estadísticas para el análisis de tendencia central, dispersión y forma de bases de datos institucionales (como el Instituto Nacional de Estadísticas y Censos, INEC) resultó sumamente útil y complementario al trabajo cualitativo. 


\section{Los sujetos}

Se muestra seguido una breve descripción de las personas cuyas memorias alimentan este trabajo. Todos los nombres usados son seudónimos.

Miguel: Tiene 71 años, vive en San Pedro desde que nació, se considera un "pedreño" nato pues hasta sus bisabuelos ya vivían en el mismo lugar que él ahora (sector el Bosque). Actualmente, está pensionado, fue jugador de futbol en Heredia, dirigente comunal, estuvo en la Guardia Civil, trabajó en el Instituto de Tierras y Colonización (ITCO) y, por último, en el Banco de Costa Rica.

Zulay: Tiene 75 años, vive en el Bosque y proviene de una familia de larga tradición de participación en actividades religiosas y políticas. Su esposo, Antonio “Toño", fue el encargado de reventar la pólvora de las dianas y guiar a los "payasos" durante casi toda su vida. Su papá era oriundo de San Pedro, su madre de San Joaquín de Heredia. Recuerda que su padre tuvo una pulpería y que las dianas siempre hacían parada en su casa; como los payasos le daban miedo, salía corriendo al cafetal y recuerda que su papá la traía en brazos y le mostraba "que los payasos eran gente". Además, recuerda que su deporte favorito era "resbalar tabla" en los potreros, "eran como las patinetas hoy".

Sofía: Tiene 82 años, fue la primera maestra de la escuela de San Pedro de Barva, dio clases ahí casi toda su vida, siempre ha vivido frente al parque. Recuerda que en las dianas de su niñez, los payasos "no pegaban", sino solo bailaban y se tocaba pasos dobles y boleros. Su esposo, de apellido "Ulate", también tenía una pulpería frente a la iglesia. Ella recuerda que en lo que ahora es parque, antes había una plaza donde las carretas venían a "mercar" producto desde Birrí (norte de Barva).

Asdrúbal: Tiene 63 años, vive en Heredia, pero su familia es originaria de San Pedro y ahí ha trabajado toda la vida en su taller de mecánica y soldadura. Fue instructor de artes marciales y jugador de futbol. Se considera un habitante nato de San Pedro: "yo vivi toda la vida aquí en San Pedro hasta que me casé a los veinte años; cuando me casé, me fui a vivir a Heredia, pero siempre seguí conectado con el pueblo, nunca me separé...".

Benjamín: Tiene 40 años, es sobrino de Asdrúbal, también trabaja con él en soldadura y mecánica. Le conocen como "pin compita", ha vivido en San Pedro toda su vida. Recuerda que para la diana, su abuela lo llevaba a trabajar en la organización de las fiestas para el pueblo.

2 Vender, intercambiar, comerciar. 
Alberto: Tiene 30 años. Llegó a San Pedro a los once años, vive en la calle "Los Vegas" desde entonces. Ha trabajado como polaco, electricista, soldador y operario de construcción. Creció con su abuelo, "Miguel música", quien fuera originario de San Pedro.

Juan: Es el hijo mayor de Asdrúbal, tiene 40 años. No vive en San Pedro, sino en Heredia, pero se considera miembro de la comunidad, al igual que su esposa e hija. Ha trabajado como polaco y heredó de su padre el oficio de soldadura y mecánica. Recuerda que siempre asistió a los bailes en las noches antes de la diana.

¿Por qué ellos y ellas? Las personas informantes clave, a partir de quienes se realiza este trabajo de comprensión del espacio como construcción social, se caracterizan por ser habitantes originarios de la comunidad; es decir, nacieron y aún viven ahí; sus padres también estuvieron antes que ellos y ellas e incluso hasta sus abuelos y abuelas. Además, algunos pertenecen a las familias con tradicional presencia en las estructuras políticas, religiosas y económicas. Una característica metodológicamente interesante es que todos tienen edades cuyas diferencias permiten que sus memorias compartan los mismos espacios, pero en "etapas" diferentes de la vida humana (niñez, juventud, adultez). Esto implica que el "recordar ahora" posiblemente esté fuertemente influenciado según la etapa en que se vivió. Por ejemplo, el recuerdo de un potrero en 1950 para quien fuese un niño sería el juego; para el joven, quizá ya el trabajo y para el adulto, la familia. Finalmente, el sector específico de la comunidad donde han vivido también es un factor considerado en su selección.

\section{Descripción etnográfica de la diana en San Pedro de Barva}

El planteamiento de la producción social del espacio a partir del proceso ritual toma a la diana como ese lapso recurrente en el calendario, donde elementos de la estructura (relaciones, roles, posiciones, prácticas, normas) se tornan ambiguas, se invierten, se polarizan, dando paso a una especie de "anti-estructura" (pero no caótica y carente de sentido), de manera que por un momento la realidad cotidiana se vuelve experiencia simbólica y el sujeto se posiciona física y socialmente en una dinámica inter-estructural. Este "espacio" que se produce en la diana, además de su universo religioso, político y económico, implica la reafirmación e incluso resolución de las formas identitarias que generan la noción de comunidad entre sus miembros.

Sobre las festividades tradicionales que implican mascaradas, principalmente en el Valle Central de Costa Rica, Gisselle Chang en su obra "Máscaras, mascaradas y mascareros" explica que su origen se remonta a la época colonial (Chang, 2007). La autora también coincide junto con otros autores en que a pesar de su origen, principalmente en el medioevo europeo español, al llegar a América de la mano de los conquistadores, la práctica de las mascaradas y las dianas se ven influenciadas por otros grupos humanos del contexto, principalmente población indígena pero también africana y asiática (Chang, 2007). 


\section{Fase pre-liminal: "La noche antes"}

La fase preliminal consiste en el momento cuando los sujetos se "separan" de la vida cotidiana y entran al estado liminal. La noche antes de la diana presenta esta característica. Se acostumbraba pasar la noche y la madrugada en el parque, la gente se reunía ahí a conversar, tomar licor, de vez en cuando llegaba algún grupo de músicos de cimarrona. Si había turno, posiblemente también implicaba juego de pólvora o un baile con "conjunto"3. "Yo la esperaba ahí en el parque tomando vino, guaro e'caña, puros y comida y la vara y ahí llegábamos a la payasada y esas voladeras de pichazos ${ }^{4}$, sea tan guevón ${ }^{5}$, era un despiche ${ }^{6}$ esa vara” (González, 2014, pág. 132).

Se organizaba todo mundo muy loco, ah mae, era excelente, era un montón de familias, digamos que ya tipo tres, tipo cuatro de la madrugada cuando salía el baile, eran un pichazo ${ }^{7}$ de familias, siempre se hacía baile con conjunto antes de las dianas, ahí en el Caracol o en el Multiuso, antes de la diana, ¿usted no sabía eso?, siempre había eso. Yo con Juan era pa' arriba y pa' abajo tomando birras y comiendo... Era un conjunto bravo ${ }^{8}$, con música para $\operatorname{rocos}^{9, ”}$ (González, 2104, pág. 132).

En el parque coinciden jóvenes, algunas familias enteras, vecinos de otras comunidades, inclusive hay casos de personas que se han ido de San Pedro a vivir a otros lugares pero regresan para ese día específicamente. No obstante, los espacios para la espera de la diana no se limitan al parque, sino que también incluyen las calles, bares cercanos, la plaza, entre otros. En realidad, durante esa noche hay gran movimiento de gente en las principales calles de la comunidad.

Es interesante destacar que la diana y su "espera" desde la noche anterior ya no solamente representan una celebración religiosa para el santo de la comunidad, sino que está imbricada de motivos relacionados con la amistad, la compañía, la repetición de un encuentro que se alimenta del recuerdo de anteriores pero no se limita a estos. Son características de un proceso cultural complejo de analizar, pues se parte de una actividad religiosa que termina creando identidad y sentido de pertenencia. Esto se puede analizar en las palabras de un joven durante la noche antes de la diana del 2010.

\footnotetext{
3 Algún grupo musical

4 Golpes

5 Cabrón, necio

6 Desorden

7 Muchas

8 Bueno, excelente

9 Adulto
} 
"Bueno, ambiente previo a la diana, igual que todos los años, lo vivimos, lo disfrutamos, lo bonito es compartir con los amigos, gente de otros pueblos cercanos que vienen aquí a compartir con nosotros y sinceramente es muy bonito, porque es volver a años atrás que se vivieron cosas similares, pero tal vez este año son cosas mejores, nos encontramos nuevamente con los amigos que no veíamos quizá desde hace un año y ahora tenemos la oportunidad de volverlos a ver y compartir con ellos cosas que no habíamos hecho antes, tal vez por trabajo, por las novias (risas)... son la una de la mañana y estamos a cuatro horas de arrancar..." (González, 2104, pág. 134).

¿Qué papel representa esta espera por la diana? Posiblemente una prueba, un esfuerzo que deben hacer los sujetos para derivar en la noción de un colectivo que se reúne en un espacio que ha suspendido temporalmente su código de comportamiento "normal" para dar paso a un estado liminal; no obstante, también cargado de representaciones de los estatus y roles de la estructura social.

Para efectos del estudio de la producción social de espacio, se destacan estos elementos del fenómeno que desde cierta frontera de la estructura social toman espacios simbólicamente centrales y comienzan ahí a mostrar atributos liminales junto con un grupo que se acerca a la forma de communitas. "Cierta frontera" significa que no es la única y de seguir el ejercicio conceptual, se llega también a la idea de que aunque las actividades de la noche antes de la diana están fuera de la organización institucional, el hecho de ser "miembros de la comunidad" sigue siendo un referente simbólico necesariamente producido dentro de la estructura social cotidiana. Me refiero a este espacio-tiempo que representa la "noche antes" de la diana, el cual no es un aspecto incluido en la organización institucionalmente legitimada, pero que, "a pesar de", está presente y tiene un aporte sustancial en el orden de acciones que derivan en el proceso ritual. Esto significa que "pasar la noche esperando" constituye una práctica espacial aparentemente fuera del sistema, pero que invierte lo que "el parque" constituye como espacio de representación dentro de los patrones normales.

La fase preliminal de la diana contiene prácticas que han resistido la transformación de los espacios de representación y la estructura de relaciones sociales, producto del crecimiento demográfico. La communitas generada ahí se destaca por la insistencia en la idea de que "el parque es del pueblo". Las personas (especialmente jóvenes) reproducen "la festividad de su santo" de una forma que les permite apropiarse física y simbólicamente de los espacios centrales de la comunidad, aún sin el apoyo explícito de las instituciones históricamente centralizadoras del dominio de estos. Resulta interesante la discusión sobre si las propiedades y atributos liminales en las prácticas sobre el espacio, alrededor del proceso ritual, se comportan de manera "fluida", es decir, se filtran por las fases preliminal, liminal y posliminal. 


\section{Fase liminal}

La fase liminal de la diana se puede visualizar como el lapso comprendido entre el estallido de las bombetas a las cinco de la mañana hasta su retorno al parque alrededor de cuatro horas después. Se describen a continuación los principales elementos simbólicos ${ }^{10}$ contenidos en esta fase del proceso ritual.

Comencemos por el símbolo que representa la actitud violenta y agresiva presente en la diana. Las celebraciones se caracterizan por incluir la persecución de los "payasos" a la gente con chilillos ${ }^{11}$ o vejigas de cerdo infladas para agredirlos, mientras bailan con las máscaras. Principalmente son los niños quienes asumen este papel, aunque también participan algunos jóvenes, en ambos casos la mayoría son varones. Se persigue y golpea a cualquier persona participando de la diana. Las agresiones pueden llegar incluso a provocar marcas en la piel.

Sobre el papel violento de este elemento simbólico, Turner argumenta que constituye parte característica de los procesos rituales donde se da una inversión del estatus en la fase liminal (Turner, 1988). En la diana, los niños enmascarados persiguen a otros y a personas adultas, mientras que estas deben aceptar los golpes y la persecución como parte de la actividad.

El análisis de la violencia presente en el acto simbólico de agredir a la gente con algún objeto puede profundizarse. Esta es parte elemental del proceso ritual, por tanto lo aporta a la producción social del espacio que logra la diana. La comunidad, en un acto repetitivo dentro de su calendario social, realiza una práctica en la que se "permite" generar violencia. A sujetos enmascarados se les atribuye el papel de perseguir y golpear a las personas participantes del rito, tanto niños, jóvenes y adultos (Figura 1). "Que le peguen" en la diana debe ser aceptado como parte del evento, semejante a un acto de sacrificio.

10 En palabras de Turner, “el símbolo es la unidad mínima del proceso ritual que todavía conserva las propiedades específicas de la conducta ritual” (1988, pág. 18).

11 Trozos livianos de las ramas de plantas de café u otras. 


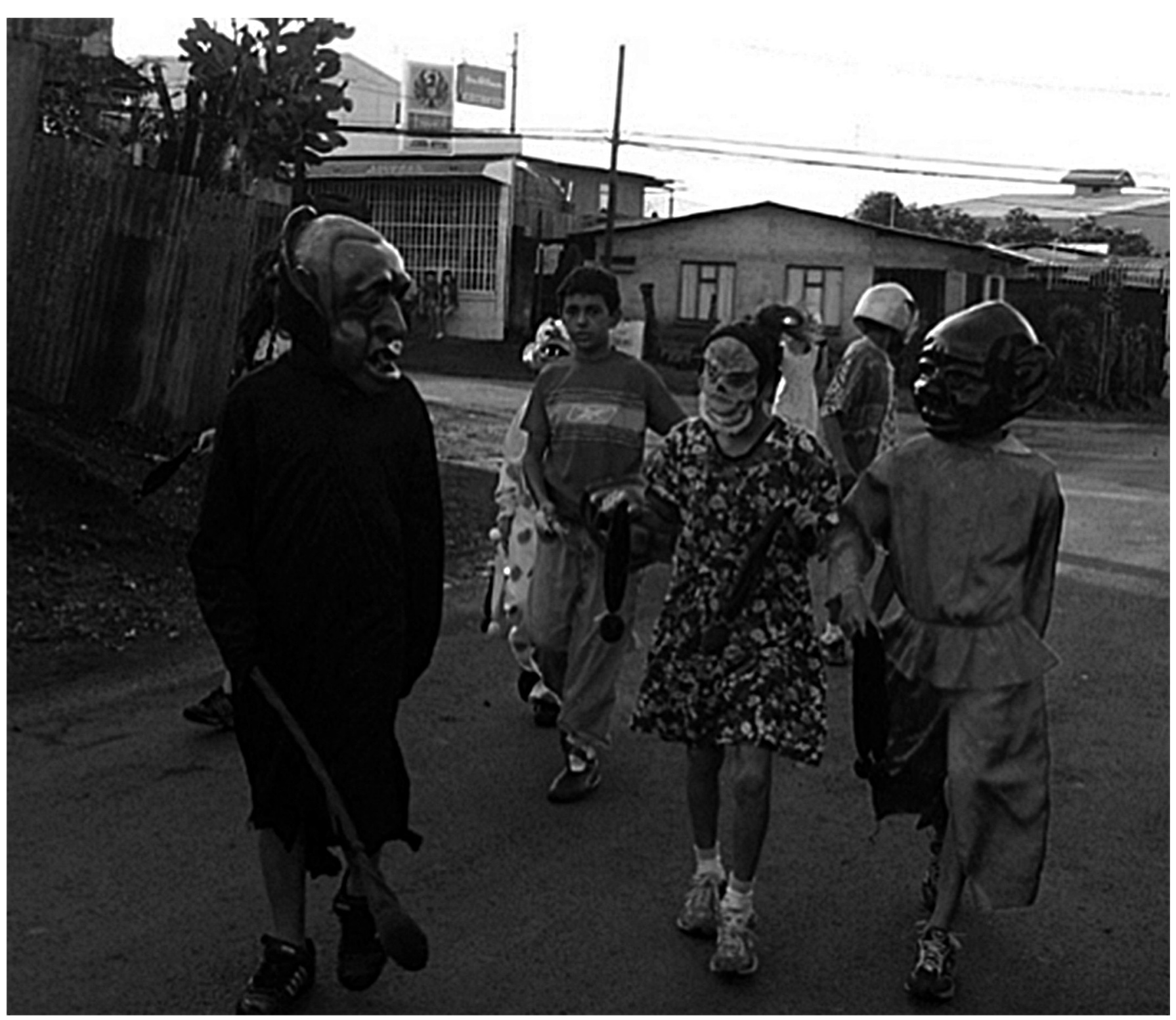

Figura 1: Niños enmascarados en la diana, 2008 (tomado de: Gonzalez [2014]).

El siguiente elemento simbólico lo constituye "la mascarada" o también llamadas "mantudas"12. Las funciones sociales de la máscara son diversas, pasando por objetos ceremoniales para identificarse con seres humanos, animales o metafísicos, para la invocación de beneficios al colectivo, también para transgredir el

12 Guiselle Chang expresa que "mantudo" corresponde a enmascarados envueltos en mantas, que desde el siglo XVII fueron conocidos en España como "mojigangas" o "boxigangas" y en América representaban personajes que anuncian festividades populares (Chang, 2007). 
orden y mostrar burla a la autoridad o para infundir temor como signo de poder (Chang, 2007). La función transformadora de la máscara en los procesos rituales constituye uno de los principales aspectos por tomar en cuenta para la descripción del espacio que produce socialmente la diana. El papel funcional-estructuralista de la máscara, Levi-Strauss lo expresa de la siguiente forma: "una máscara no es ante todo lo que representa, sino lo que transforma, es decir, elige no representar. Igual que un mito, una máscara niega tanto como afirma; no está hecha solo de lo que dice o cree decir, sino de lo que excluye” (Levi-Strauss, 2000, p. 124).

¿Qué papeles juega la máscara en la diana? La diversidad de formas ya advierte que abundan los simbolismos; no obstante, no son aleatorios ni casuales. La mascarada contiene en sus representaciones referencias a los sistemas locales y globales, haciendo de la diana una especie de drama del teatro-mundo. El espacio surrealista que construye la práctica puede reunir desde un expresidente norteamericano con otro costarricense hasta todos los miembros de una serie de televisión mexicana, sin dejar de lado a los motivos tradicionales, como la "calavera", el "diablo", el "chancho" o la "bruja".

Barva es uno de los cantones donde la mascarada forma parte de su patrimonio cultural, por lo que se permea por otras instancias de la vida cotidiana, especialmente en aquellas con importancia socioeconómica. En este sentido, la producción de máscaras es un proceso que genera mercancías. El mascarero es un personaje presente en el abanico de oficios así como el carpintero o el canastero. Su conocimiento se hereda, de forma que el apellido tiene relación con el tipo de máscara, la técnica o los diseños. Tradicionalmente se hacía de papel, goma y barro (arcilla), actualmente la fibra de vidrio sustituyó este último material.

Para poder usarla en la actividad, usualmente hay que alquilarla o comprarla. Los mascareros tienen un inventario que los días de fiestas ponen a la disposición de la gente, logrando una retribución económica por el préstamo del objeto. "Cuando estaba carajillo" ${ }^{13}$, recuerdo que tenía que hacer fila con otros chicos para tomar una máscara y usarla en la diana, a veces tenía suerte y conseguía el "Diablo". La máscara se usa con un vestido, un traje, no tiene que ser nuevo, de hecho son ropa vieja, yo le cogía los vestidos a mi mamá" (González, 2104, pág. 153).

"El ride ${ }^{14}$ de lo que eran las fiestas y turnos en San Pedro, que eso ya no se ve, era demasiado, pero demasiado familiar, como ahí casi vivían solo apellidos, ¿ya? Los apellidos, ya ahora usted ve un montón de gente, pero era lindísimo. Tal como eran las fiestas, casi que uno las olía, estaba deseando, por la hijueputa payaseada, usted duraba desde la mañana o un día antes usted apartaba la máscara, si no se le abrían ${ }^{15}$ con la máscara. Se festejaba, usted festejaba las fiestas del alma, usted las sentía, la diana usted la esperaba desde el otro día, bebiendo guaro" (González, 2104, pág. 153).

13 Niño, pequeño

14 Puede entenderse como la forma de llevarse a cabo.

15 “Abrirse con” significa popularmente robar, coger sin autorización. 
Se puede hablar de dos tipos generales de máscaras según su tamaño: cabezas y gigantes. Las primeras tienen un tamaño aproximado entre cuarenta y cincuenta centímetros, dependiendo de la complejidad del diseño. Sus motivos son variados pero principalmente hacen alusión a figuras mitológicas como la muerte, el diablo, animales, entre otros. Cubren toda la cabeza dejando solo el espacio de los ojos, nariz y boca libres. Los gigantes, usualmente son de mayor tamaño, usan trajes coloridos que simulan tener también brazos, a lo interno, se sostienen de una estructura metálica para colocarse sobre los hombros de quien los porta.

Hasta finales del siglo XX, los motivos de los gigantes hacían referencia a una pareja de personas distinguidas. "La giganta" es una señora blanca, a veces rubia, usa maquillaje, aunque también puede tener variaciones. "El gigante" repite la fórmula, blanco, a veces usa bigote, otras no. Posiblemente ambos personajes representan una burla o remedo a la autoridad colonial.

Zulay recuerda que la gente "veía pasar a los payasos", y resalta también la cuestión del tipo de música que se practicaba, lo cual desde su memoria era "todo un espectáculo" ver danzar a los payasos junto con la cimarrona.

"Eh... no sé si decirle que... que mejor que las que hay ahora o no, ¿verdad?, porque no sé. Pero si yo me acuerdo que antes no andaba la gente con los payasos, entonces eran solo los payasos y la música, bailando. Bailaban mucho los payasos, eso era lo atractivo, uno salía al portón a ver los payasos bailar, porque era que bailaban, no correteaban como ahora, sino que ellos bailaban y no pegaban. Me acuerdo que papá los traía aquí a mi casa, a esa casa de adobes, en esa casa de adobes había un corredor inmenso al frente, entonces había lo que llamaban bancas, unos escaños, unas bancas, y ahí los sentaba y les daba café y les daba un chinche (traguito), verdad" (González, 2104, pág. 156).

Sofía también recuerda al baile y destaca un elemento interesante presente igualmente en la memoria de Miguel, los “cantores".

"Sí, siempre existieron, sabe otra cosa qué existía, hombres que hacían payaso, como esos Vegas de ahí arriba, me acuerdo yo que cantaban unas cosas como: 'cuando chico panza tocaba la pianola, todas las viejillas alzaban la cola', entonces él bailaba y hacía la música. Esa gente eran muy amigos de ayudar a esas fiestas de San Pedro (González, 2104, pág. 156).

Se destacan personajes clave en el escenario, como el diablo, la calavera, los cuales junto a los gigantes puede que representen parte del imaginario relacionado con los tiempos de la conquista y colonia. El gigante y la giganta pueden representar a los españoles, mientras que el diablo y la calavera son representaciones del mal infundado por las creencias católicas, sin embargo, como en muchas otras manifestaciones latinoamericanas, terminan siendo inversas a su significado original, pues también simbolizan la broma y la burla hacia las clases dominantes. 
"Máscaras muy bonitas, sí, recuerdo que muy bonitas y el vestido, digamos el diablo, siempre me acuerdo del diablo que se lo ponía un señor alto, que ya murió él, era alto, y entonces el abría los brazos, y al abrir los brazos, el vestido era rojo y al abrir los brazos, se le veía todo esto debajo de los brazos negro, impactaba mucho, porque eran y eran vestidos largos, no como ahora que se ponen unos medios puestos, cuando eso eran máscaras muy bien detalladas..." (González M. , 2104, pág. 157).

Para la primera década del siglo XXI, las representaciones de las máscaras amplían su repertorio, dejando de lado al "señor y señora" coloniales, para dar paso a figuras de la política local e internacional, la industria cultural globalizada o influencias de fenómenos como la multiculturalidad. En principio la motivación es económica. Los trabajos de los mascareros llegan a otros espacios debido a la importancia y atención que adquieren por la creciente exposición del arte barveño. La declaración del día de la mascarada tradicional costarricense mediante Decreto Ejecutivo N. 25724 en 1996 contribuyó a que el fenómeno de las mascaradas adquiriera relevancia política y socioeconómica. Posiblemente otros fenómenos nacionales en la primera década del siglo XXI también influyeron en la diversificación de las representaciones en las mascaradas, por ejemplo el periodo de discusión y lucha sobre el Tratado de Libre Comercio con Estados Unidos.

Así, el cambio en los motivos incorpora personajes afrodescendientes (usualmente una pareja de adultos vestidos con coloridos trajes), dos expresidentes nacionales (Oscar Arias y Abel Pacheco) y uno norteamericano ${ }^{16}$, figuras de series de televisión (el chavo por ejemplo) y sujetos locales (algún personaje con particularidad económica, política, o también algún "loco del pueblo").

Siguiendo con la descripción de elementos simbólicos, el siguiente lo constituye "la cimarrona". Se refiere al grupo de músicos que acompaña la diana. Está compuesta de instrumentos de viento (usualmente los llamados "bronces", es decir trompeta, trombón, tuba, saxofón) y percusión (bombo, redoblante, platillos y güiro). Se conforma entre cuatro y diez personas, con edades variables, en su mayoría son varones entre los 15 años hasta incluso adultos mayores a 65 años. Su estilo musical es principalmente el denominado "parrandera".

En Barva ${ }^{17}$, estos ensambles musicales y producción de máscaras han crecido significativamente, haciendo que su presencia sea esperable no solo en eventos públicos, sino privados como los aniversarios, matrimonios, graduaciones, etc.

16 No es cualquier presidente de Estados Unidos, se retrata a George Bush hijo, curiosamente en una década donde parte de la atención internacional giraba alrededor de las políticas bélicas de ese país y la "guerra contra el terrorismo" llevada al Medio Oriente.

17 También se repite en otros cantones de Heredia y Cartago principalmente. 
Formar parte de una cimarrona o una mascarada se ha vuelto un tipo de oficio con notable presencia entre los y las jóvenes en el cantón. Para el 2012, solo en San Pedro de Barva podían contratarse hasta cinco distintas, la mayoría de personas menores a 25 años. Los nombres de las estas son variados tanto en formas como razones, por ejemplo "los tibios", "los primos", "los colegas", "pura vida", "folklórica pedreña", "los gemelos".

Marx decía que para entender el capitalismo como modo de producción habría que reconocer el carácter fetichista de la mercancía. El valor del trabajo es un jeroglífico social, por medio del cual toman forma las relaciones entre sujetos en función de las posiciones en la estructura y superestructura del sistema (Marx, 1873). Esto implica que el espacio socialmente producido por el capitalismo o por sus influencias debe permitir identificar como mercancías (es decir valor de cambio a partir de valor de uso) a los elementos socioculturales que no precisamente se originan en las prácticas del mercado, pero que terminan formando parte de sus lógicas.

Las máscaras y la cimarrona, como elementos socioculturales de la diana, tienen sus orígenes en espacios-tiempos distintos al relativamente reciente contexto capitalista. De hecho, su presencia se remonta a los sistemas globales de la Colonia (1502-1821) y la posterior República (1821-1948). No obstante, en el actual contexto capitalista, ambas pueden ser vistas como resultados de la conversión del trabajo humano en valor de cambio, es decir, mercancía.

El origen de las cimarronas se atribuye a las bandas municipales de principios de siglo XX y el nombre (cimarrón) alude a un tipo de animal ruidoso (Cedeño, 2013). En el Diccionario de la Real Academia Española, significa "dicho de un animal doméstico que huye al campo y se hace montaraz, se decía del esclavo que se refugiaba en los montes buscando la libertad". No deja de ser interesante la relación entre el significado de la palabra y su papel en la diana, pues otra forma como se le conoce es "la espantaperros". Cuando y por qué se comenzaron a llamar así es difícil de ubicar, posiblemente pueda proponerse el contexto de las comunidades coloniales junto con la actividad ganadera; sin embargo, su uso se encuentra extendido en Cartago e incluso Guanacaste.

Una opinión común entre los y las informantes es que la cimarrona que toque en la diana debe ser "propia" de la comunidad, es decir que sus miembros sean parte de San Pedro. Esta es interesante de describir. Esta cimarrona nació como un proyecto de escuela musical y desde hace más de quince años ha participado de las festividades religiosas tanto como las procesiones en Semana Santa así como de las dianas y fiestas privadas. Esta cimarrona mantiene algunos de sus miembros originales, pero también ha permitido ingresos de niños, niñas y jóvenes que inician en la música, dándose así cambios generacionales que se perciben incluso en el repertorio y los ritmos. De los boleros y pasos dobles se pasó a las cumbias, merengues, salsas y hasta ritmos suramericanos como la samba y la bossa nova. 
A la cimarrona se le debe pagar por hora, por ello se recolecta dinero días antes. Es común también en medio de la diana que se pida dinero adicional para pagar más tiempo de música, llegando incluso a tocar más de cuatro o cinco horas seguidas.

El siguiente elemento simbólico lo constituye el "compuesto arreglado". En la diana es tradicional el consumo de licor de contrabando o licor ilegal, ya sea en una versión pura (llamado licor de contrabando) o mezclado con diversos ingredientes como frutas. La versión mezclada tiene varios nombres, entre ellos "compuesto", "pedo'e chancho" y "leche de burra". Días antes de la actividad, hay gente que se organiza para producir varios galones de este licor, entonces un encargado se dedica a recolectar dinero para la compra de los ingredientes y él mismo puede producir la mezcla. Existe una variedad de mezclas que incluso llegan a ser exclusivos de la persona que los produce. Usualmente el licor lo beben solo adultos, pero no es difícil que menores de edad accedan a él. "Eso es un compuesto que se hace desde hace años, nosotros le echamos leche de coco, eh, soda, un poquito de sirope de coco, también un poco de leche evaporada. Esto es una tradición, de hecho en toda diana tiene que haber buena cimarrona y buen trago" (González, 2104, pág. 165).

El último elemento por describir se le conoce como "el dedicado". Durante el recorrido de la diana, esta debe detenerse en puntos específicos. Los "dedicados" son las personas o familias por las que la diana deja a la calle como su principal espacio y entra en sus casas. Se trata de grupos familiares que han apoyado económicamente a la celebración, usualmente se trata de los mencionados "mantenedores".

Ahí, los miembros del grupo familiar han preparado pan, café e incluso hasta "gallo pinto"18 y sirven a las personas que participan de la diana, incluyendo a la cimarrona. Esta práctica implica dos operaciones interesantes. En primer término, produce una especie de transformación del espacio privado en público. La casa donde la diana se detiene se convierte en parte de la calle, la gente entra, baila, las máscaras corren y no hay una limitación visible que impida a alguien ingresar a un lugar que en otros momentos es un lugar privado.

En esto vuelven a ser fundamentales los papeles que juegan las familias más pudientes de la comunidad, los mantenedores, pero además se debe rescatar el sentido de solidaridad que acompañaba la celebración de la fiesta del santo patrono. Es interesante ver cómo este proceso ritual implica que los pobladores con mayores recursos económicos lleven a cabo "banquetes", que si bien incluyen un sentido de la solidaridad y convivencia, también permiten que estos reflejen su capacidad económica y por tanto sean manifestaciones de poder.

18 Comida tradicional costarricense compuesta de arroz, frijoles y especies, suele servirse como plato del desayuno. 
Zulay narra una curiosa anécdota de la participación de un mantenedor para la fiesta patronal de la comunidad. Se puede notar definitivamente que la condición de este implicaba acceso a recursos y capital económico.

“Alguien por ahí me contó una anécdota que el papá le dijo a ellas, a las muchachas, me nombraron de mantenedor, ¿que prefieren? ¿Qué yo haga unas buenas fiestas, con juego pólvora y bastante pólvora?, porque antes las doce, tenían que ser doce, ¿Qué haga unas buenas fiestas o que les compre estrenos ${ }^{19}$ a ustedes? Porque antes solo se estrenaba, aquí en San Pedro solo se estrenaba para el día de San Pedro y para diciembre. El día de San Pedro era importantísimo, el que no estrenaba no salía. Se lo estoy contando porque yo lo viví... Dice que las muchachas le dijeron al papá: "ah no, nosotras no nos interesa la función de San Pedro, nos interesa estrenar"...entonces no sé si el señor lo estaba diciendo en serio o sería una broma, pero que ellas dijeron ¡no, a nosotras nos interesa estrenar, usté sabrá que hace!...” (González M., 2104, pág. 169).

\section{Fase posliminal}

La diana inicia en el parque y retorna a él, los recorridos pueden ser variables, pero el inicio y el fin son en el centro de la comunidad, es decir, el parque y la iglesia. Al llegar ahí, la cimarrona toca aproximadamente una hora más hasta que dé inicio la misa a las diez de la mañana (Figura 2). Los músicos se marchan, las máscaras se guardan y la gente parte a sus casas. Los espacios que abarcó la diana regresan a sus patrones y axiomas cotidianos y el calendario continúa su marcha hasta que las explosiones en el cielo anuncien la nueva celebración.

La fase posliminal, teóricamente apunta a ese retorno de los sujetos a la estructura. Para el caso de un ritual de inversión de estatus, este regreso al sistema no implica una nueva posición (como se esperaría de un rito de paso). Aun así, el proceso ha permitido, una vez más, "dar vuelta" al ciclo de acciones que componen la construcción social del llamarse "pedreño" o "pedreña".

En las dianas recientes (2007-2013), la misa realizada después de la diana no manifiesta diferencias significativas con las realizadas en otros días. No obstante, para la segunda mitad del siglo XX, en los relatos de Miguel y Sofía sobresale la llamada "misa de revestidos”. "... Había personas que se llamaban mantenedores, y esos ocho días de fiesta, Leonora Ulate y Emilio Solís se hacían cargo de traer los padres, de traer los arzobispos, de traer todo lo que se necesitaba" (González, 2104, pág. 171).

19 Vestir ropa nueva en días festivos. 


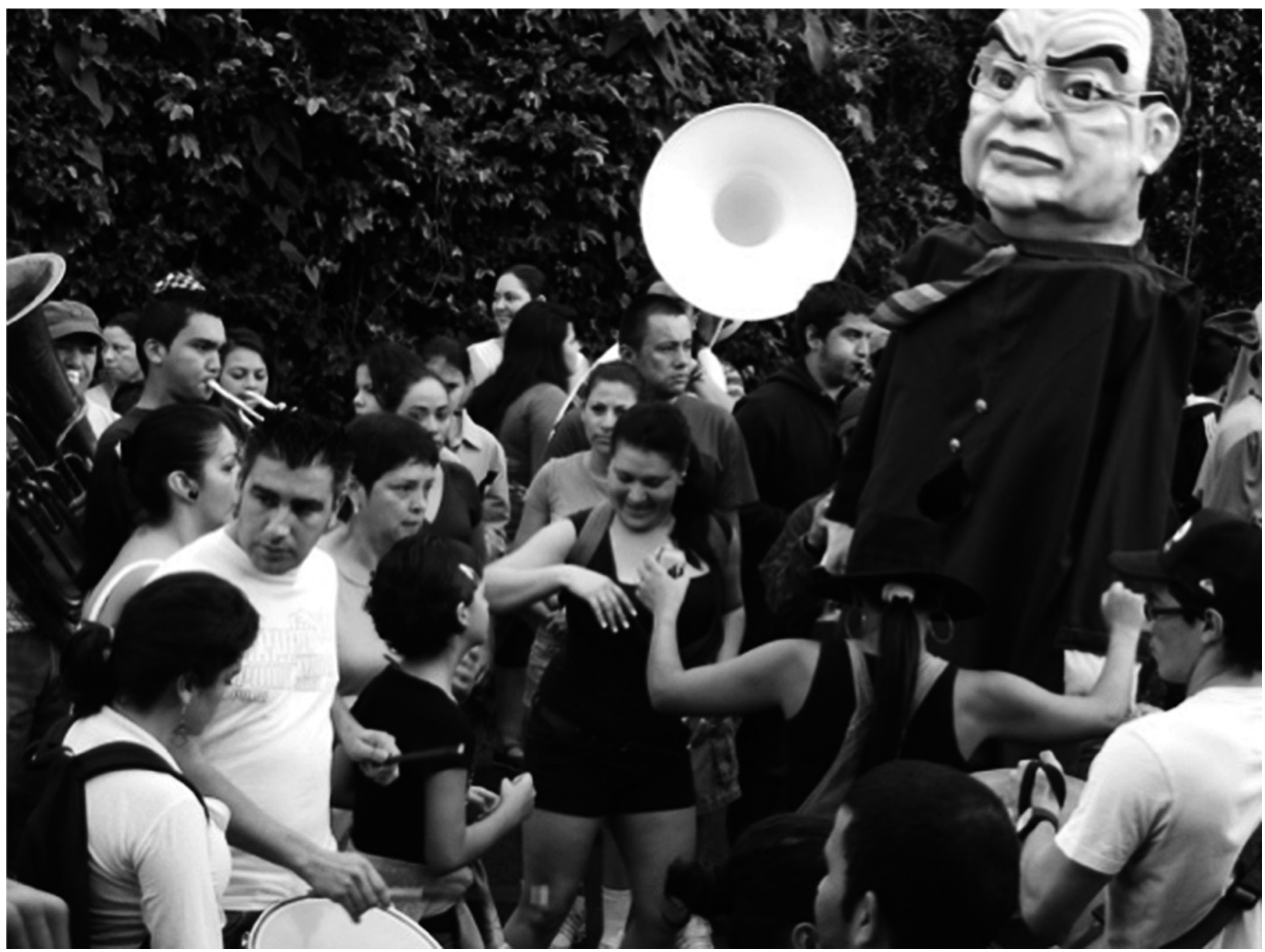

Figura 2: Diana San Pedro de Barva, 2009 (tomado de: Gonzalez [2014]).

"Este señor, don Andrés, era el encargado de la misa de revestidos, eran como cinco padres, cinco o seis padres y venía muchísima gente y ahí donde está la pulpería de Lelel, eso era una casa grande del tiempo de antes y ahí empezaban desde quince días antes a cocinar el arracache, hacer pan casero, yo iba, porque el papá de Lelel, era tío mío. La misa era a las 9, terminaba a las once y todos los padres subían y era un almuerzo... todo eso lo ponía el finado Andrés Ulate" (González, 2104, pág. 171). 
Desde una perspectiva materialista, en esta "misa de revestidos" se evidencia una fuerte relación entre los grupos religiosos del momento y los esfuerzos de los mayordomos y mantenedores ${ }^{20}$ por mostrarse y ser reconocidos como económicamente capaces de "poner" lo necesario para actividades de la comunidad. Se puede inferir por tanto que el retorno a la estructura (fase posliminal) funcionó también a manera de escenario para el encuentro de clases socioeconómicas, religiosas y políticas, además de mecanismo de ingreso a los habitantes migrantes.

\section{Reflexión: La producción social de espacios desde la diana}

Si la noción colectiva e individual de la categoría "espacio" se entiende como resultado (producto) de procesos sociales llevados a cabo por sujetos específicos en sitios y tiempos particulares del calendario cultural, se puede intentar una descripción de los atributos de un lapso " $n$ " cualquiera de dicho ciclo, en términos de: a) prácticas espaciales, b) espacios de representación y c) representación de los espacios (Lefebvre, 1991). El resultado podría verse como las características del "espacio cotidiano". En la misma línea, también se podría realizar una descripción de los atributos del espacio de la diana en el lapso " $\boldsymbol{D}$ " con las mismas variables "lefevbrianas", además de incluir los elementos simbólicos presentes en las fases rituales del proceso de inversión de estatus (Turner, 1988). Es posible también sumar al análisis el conjunto de atributos del lapso posterior a la diana $\boldsymbol{D}+\boldsymbol{t}$.

Los procesos que generan los atributos para ambos momentos del calendario social revelan las convergencias y divergencias entre el "espacio cotidiano" $\boldsymbol{n}$ y el "espacio ritual" $\boldsymbol{D}$. No se puede afirmar que n es completamente igual o diferente a $\boldsymbol{D}$, pues son fenómenos multifactoriales y dinámicos. Pero su comparación permite evidenciar las formas del espacio socialmente producido en ambos escenarios. El asunto radica en ver acciones elementales que diferencian los procesos, no en su mecanismo, sino en el resultado sobre la experiencia individual y colectiva de los sujetos que participan. Estas pueden ubicarse en los planos relacional, histórico e identitario (Augé, 2000).

Entonces, desde el argumento anterior, los atributos del espacio ritual $\boldsymbol{D}$ implican para el sujeto y el colectivo una serie de experiencias simbólicas significativamente diferentes a los atributos del espacio cotidiano $\boldsymbol{n}$. Incluso el sistema social no cambia radicalmente posterior al espacio ritual $\boldsymbol{D}+\boldsymbol{t}$ (pues como ya se ha mencionado, no es un rito de paso, sino un rito cíclico de inversión de estatus). ¿Cómo lo realiza entonces la diana? Parte de la respuesta puede hallarse concentra en las prácticas y representaciones limi-

20 Mayordomos y mantenedores se le conocía a los miembros que apoyaban la organización de actividades relacionadas con las cofradías de la colonia, el uso de los términos permanece aún a finales del siglo XX en la comunidad de San Pedro de Barva (González, 2014). 
nales presentes en el proceso ritual. La liminalidad presente en la diana participa en conservar activos los discursos locales sobre la: a) identidad "pedreña", b) las fronteras físicas y simbólicas y c) la estructura de relaciones sociales. La diana contribuye a mantener viva en la experiencia de los sujetos la noción de San Pedro como "lugar".

Las dianas del siglo XXI han incorporado a la lógica de sus recorridos a aquellas áreas urbanizadas con proyectos de vivienda para clases socioeconómicas media-baja ("urbanización" Vistas del Bosque por ejemplo). Estas zonas se componen de habitantes, en su mayoría personas provenientes de cantones cercanos (Heredia, San Rafael, San Pablo, etc.) quienes al llegar a la comunidad, se integran a los sistemas locales públicos de educación, salud, seguridad, posiblemente por las ventajas materiales que implica. Al pasar la diana por estas “nuevas calles”, logra una especie de incorporación al tejido identitario local que el espacio físico materializa. Por el contrario, esto no ha sucedido con los proyectos urbanísticos con mayor valor del bien inmueble ("residencial" Doña Elena), con características socialmente relacionales contrarias de los otros recién llegados. Por lo general estas familias acceden a sistemas "espacialmente" localizados en otros contextos. Se les conoce popularmente como "residenciales dormitorio" y se refiere al fenómeno de espacios urbanizados donde los sistemas de relaciones sociales (trabajo, educación, política, salud, etc.) se localizan en otros lugares y su residencia se limita prácticamente a las actividades de descanso, sueño, es decir el final del día. La mayor parte de la red social está "fuera" de los tejidos locales y las relaciones de vecindad son mínimas o nulas. Esto hace de la diana un ritual de la comunidad que sirve de mecanismo discriminatorio para la integración identitaria de nuevos sujetos sociales.

Por tanto, se observa que esta práctica no solamente refleja la estructura social de la comunidad y su entorno, sino además logra la adaptación a una parte del crecimiento poblacional que influencia la dinámica territorial, que a su vez es resultado de la incorporación de los nuevos sujetos a los sistemas locales de relaciones sociales (población de las recientes urbanizaciones).

La mirada hacia el papel del enmascaramiento en el proceso ritual permite una inferencia teórica particularmente pertinente a la comprensión del espacio como constructo cultural. Turner afirma que en la inversión de estatus, la máscara provee un anonimato que permite agresión y no humillación (Turner, 1988). Esta condición anónima, de personalidad suspendida, se lleva a cabo en un espacio, que si bien es cierto muestra atributos liminales, sus componentes simbólicos son tomados de los roles y estatus de los sistemas locales y globales. El parque, las calles y las casas de los dedicados se convierten en espacios de representación reflejo de la estructura social, pero con un sentido inverso. Las máscaras del gigante o el diablo, el recorrido de la diana (vista como un refrescamiento de la noción de centro y frontera del espacio al cual se adscribe la identidad) les permite a los sujetos cotidianos, miembros de la comunidad, tomar la representación de un rol o estatus superior con licencia de un acto de agresión hacia los demás miembros, que aceptan el mismo como parte de las dinámicas del proceso ritual. 
En resumen, la diana implica entonces un espacio de representación, donde los personajes o elementos simbólicos son tomados de la estructura social cotidiana: roles, estatus, esquemas de las jerarquías socioeconómicas. Este espacio tiene atributos liminales, es decir se suspenden las normas y axiomas normales de la cultura que los produce. El parque, las calles, en general el territorio de la comunidad es tomado por sus miembros en una serie de prácticas espaciales que son distintas en el calendario general, pero que en esa fecha adquieren posibilidad, a través del proceso ritual de inversión. Mediante el enmascaramiento, estos personajes pueden ser representados por personas miembros de la comunidad, pero que gracias a la eficacia de la máscara, obtienen un anonimato que les permite dos acciones: bailar y pegarle a la gente. El distrito se transforma en un gran escenario que convoca a personajes del pasado colonial, con la industria cultural globalizada (medios de comunicación) y la política nacional e internacional.

\section{Referencias bibliográficas}

Augé, M. (2000). Los no lugares. Espacios del anonimato. Una antropología de la sobremodernidad. Barcelona: Gedisa.

Cedeño, N. (2013). Historia de la cimarrona en Costa Rica. Expresiones y manifestaciones. Sistema de Información Cultural, Costa Rica, recuperado de: http://si.cultura.cr/component/sicultura/articulo/historiade-la-cimarrona-en-costa-rica-2944.html

Chang, G. (2007). Máscaras, mascaradas y mascareros. San José: Centro de Investigación y Conservación del Patrimonio Nacional, Ministerio de Cultura y Juventud.

Da Mata, R. (2002). Carnavales, malandros y héroes. Hacia una sociología del dilema brasileño. México: Fondo de Cultura Económica.

González, M. (2104). Espacio, ritual y estructura social: el amanecer de los mantudos y la espantaperros. Producción social de espacio en la prática de la diana, San Pedro de Barva (Tesis de maestría inédita). Universidad de Costa Rica, San José, Costa Rica.

Instituto Nacional de Estadística y Censo (INEC). (2014). X Censo Nacional de Población y VI de Vivienda 2011. Resultados generales. San José. Recuperado de http://www.cipacdh.org/pdf/Resultados_Generales_Censo_2011.pdf

Instituto Nacional de Vivienda y Urbanismo (INVU). (2012). Plan de Ordenamiento Territorial de la Gran Área Metropolitana de Costa Rica 2011-2030. Recuperado de: http://www.mivah.go.cr/Documentos/ potgam/PROPUESTAS-3_21_AGOSTO_2012.pdf

Lefebvre, H. (1991). The production of space. USA: Blackwell.

Levi-Strauss, C. (2000). La vía de las máscaras. México: Siglo XXI editores.

Marx, K. (1873). El capital (Tomo 1). Moscú: El Progreso.

Turner, V. (1988). El proceso ritual. Madrid: Taurus Alfagura S.A. 